\title{
MATAVIMŲ REZULTATŲ, GAUTŲ MATUOJANT SUDE்TINGOS GEOMETRINĖS FORMOS DETALES 3D SKENERIAIS IR KOORDINATINE MATAVIMO MAŠINA, LYGINAMOJI ANALIZE்
}

\author{
Žilvinas GRAIBUS ${ }^{1}$, Vadim MOKŠIN ${ }^{2}$ \\ Vilniaus Gedimino technikos universitetas, Vilnius, Lietuva \\ El.paštas: 'zilvinas.graibus@stud.vgtu.lt; ‘vadim.moksin@vgtu.lt
}

\begin{abstract}
Santrauka. Straipsnyje lyginami dviejų detalių matmenų matavimų rezultatai, gauti skirtingomis matavimo sistemomis: koordinatine matavimo mašina (KMM), 3D lazeriniu skeneriu ir 3D fotometriniu skeneriu. Buvo matuojamos iškilaus ir igaubto paraboloidinio profilio detalès. Išanalizavus matavimo rezultatus gauta, kad KMM matavimo sistema gauti rezultatai pagal Stjudento $t$ kriterijų ( $t$-test) statistiškai reikšmingai $(p<0,001)$ tikslesni už rezultatus, gautus 3D lazeriniu ir fotometriniu skeneriais. Taip pat nustatyta, kad rezultatai, gauti 3D lazerine skenavimo sistema, yra statistiškai reikšmingai tikslesni $(p<0,05)$ už gautuosius 3D fotometrinio skenavimo sistema.
\end{abstract}

Reikšminiai žodžiai: KMM, fotometrinis skeneris, lazerinis skeneris, 3D modelis.

\section{Ivadas}

Dèl didèjančių lūkesčių gaminių kokybei vis daugiau ieškoma našesnių ir tikslesnių būdu gaminiu kontrolei užtikrinti. Pirmosios koordinatinès matavimo mašinos (KMM) buvo išrastos dar XX a. 5-ajame dešimtmetyje. Jų naudojimas labai išpopuliarèjo ịvairiose pramonės šakose. KMM gali matuoti didelị kieki ypač svarbių ir sudètingu parametrų, dažnai tuo pačiu metu (Uekita, Takaya 2016). Tai padeda sumažinti matavimo trukmę, padidinti našumą ir greičiau identifikuoti apdirbimo paklaidas. Prieš du dešimtmečius atsirado lazerinès ir fotometrinès skenavimo sistemos, bet joms vystytis trukdè gana sudètingas rezultatų apdorojimas, pateikimas ir skaitmeninimas. Dabartinès technologijos leidžia tai daryti našiau ir tiksliau. 3D (trijų matmenų) skenavimas sparčiai populiarèja dèl šių privalumų (ElMaraghy, Yang 2003): 1) didelis greitis; 2) didelè raiška; 3) nèra tiesioginio kontakto su paviršiumi; 4) atpažįstama matuojamo objekto spalva. Tai gali būti pritaikoma daugybejje sričių: archeologijoje, architektūroje, biomechanikoje ir kitose srityse, kuriose reikia objektus skaitmeninti. Metalų apdirbimo pramonèje šios sistemos dar nėra populiarios. Jų našumas yra didelis, bet ribotas matavimų tikslumas. Šiuo metu preciziniams matavimams atlikti dažniausiai naudojamos koordinatiniu matavimo principu veikiančios sistemos.
$2014 \mathrm{~m}$. buvo atlikti tyrimai (Gapinski et al. 2014), kurie leido palyginti koordinatinès matavimo mašinos, fotometrinio skenerio ir 3D tomografo sistemas. Tyrimui atlikti buvo pagamintas specialus aliuminio ruošinys, kuriame buvo išgręžtos 3,4 ir 5 mm skersmens skylès bei mechaniškai apdirbtas išorinis sferinis paviršius, kurio skresmuo $-4 \mathrm{~mm}$. Taip pat buvo išfrezuota išèma, o galiniai paviršiai apdirbti skirtingu kampu. Tyrimo metu gauta, kad KMM matavimų nuokrypiai yra 0,038 mm, fotometrinio skenerio nuokrypiai - 0,047 mm, o 3D tomografo - 0,046 mm. Šiame tyrime tiksliausiai buvo matuojama naudojant KMM, o 3D tomografo ir fotometrinio skenerio matavimų rezultatai yra panašūs. 2009 m. atlikto tyrimo metu (Cuypers et al. 2009) buvo analizuotas skirtingu matavimo metodų tikslumas, matuojant didelių matmenų (iki $100 \mathrm{~m}^{2}$ ploto) bandinius. Tyrime buvo nagrinèta mobilioji KMM sistema ir skirtingų konfigūracijų optinis skeneris. Atlikus tyrimą (Cuypers et al. 2009) rasta, kad kiekviena sistema turi pranašumų ir trūkumų. Matuojant mobiliaja KMM matavimo sistema, svarbu atsižvelgti ị užduoties reikalavimus, detalès ir aplinkos sukeliamus apribojimus. Taip pat buvo nustatyta, kad dèl skaitmeninès fotografijos ir fotogrametrijos pažangos 3D skenavimas tampa geresne KMM matavimo sistemų alternatyva. Matavimų trukmė, naudojant KMM sistemą, buvo šešios valandos, o, matuojant 3D skeneriu ir gaunant panašius pagal tikslumą rezultatus, matavimų trukmè buvo tik trys valandos. 
2015 m. atlikto tyrimo metu (Galantucci et al. 2015) buvo išmatuoti sudètingos geometrinès formos kūnai 3D tomografijos ir fotogrametrijos sistemomis. Pirmoji matavimo sistema yra tiksli, bet turi ryškų trūkumą, nes matavimams atlikti naudojami žalingi radioaktyvieji rentgeno spinduliai. Pagrindinis fotogrametrijos būdo trūkumas yra tas, kad jis negali būti taikomas didelių matmenų detalèms (didžiausieji matmenys - iki $30 \mathrm{~mm}$ ). Atlikus tyrimą (Galantucci et al. 2015) gauta, kad tikslesni matavimai buvo atlikti fotogrametrijos metodu. Buvo gauta $0,001 \mathrm{~mm}$ vidutinio kvadratinio nuokrypio reikšmè, o matuojant 3D tomografu bandinius H3, H4, H5 vidutinis kvadratinis nuokrypis siekè $0,002 \mathrm{~mm}$.

\section{Matavimo ịranga ir matuojamos detalès}

Matavimams atlikti buvo naudoti dviejų skirtingų paraboloidinių profilių (igaubto ir iškilaus) detalès (1 pav.). Jos buvo pagamintos iš aliuminio Al7075.

3D lazeriniam skenavimui atlikti buvo naudojama „Ametek" firmos skenerio sistema „Creaform Metrascan 3D“ (MetraScan 3D 2016). Šią sistemą sudaro dviejų kamerų erdvès skeneris „C-Track 780“, nešiojamasis lazerinis skeneris „MetraScan 3D“ ir kontaktinis liestukas „Handyprobe 780“. Trimačiam optiniam skenavimui buvo naudojamas „Artec“ firmos fotometrinis skeneris „Space Spider“" (Space Spider booklet 2015). Koordinatiniam gaminių matavimui buvo naudojama „DEA“ firmos KMM „Global Silver Classic“ (DEA Global Silver 2015). Naudota a)

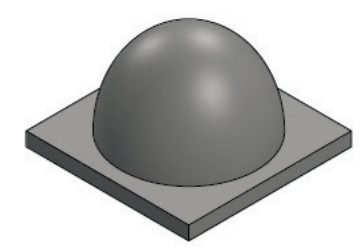

b)

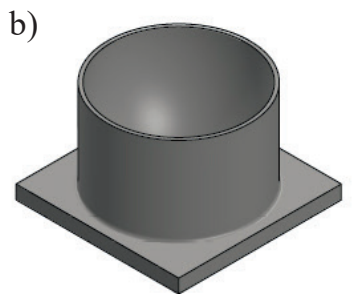

1 pav. Matuojamos detalès: a) iškilaus profilio detalè; b) igaubto profilio detalè

Fig. 1. Measured parts: a) convex; b) concave



PJŪVIS VA3-VA3

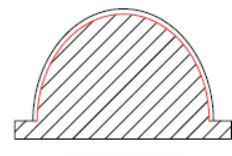

PJŪVIS VA2-VA2

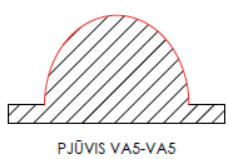



PJŪVIS VAI-VAI

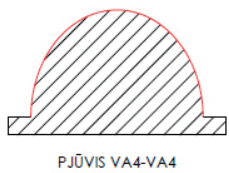

2 pav. Vertikalių pjūvių išdèstymas iškilaus profilio detalëje Fig. 2. Arrangement of vertical sections on the convex part
„Hexagon“ firmos matavimo liestuvo galvutė HH-T 5-50 (Probe heads 2015).

Detalès buvo suskirstytos 10 pjūvių - 5 vertikaliais ir 5 horizontaliais (2, 3 pav.). Pjūvis VA1 (VB1 igaubto profilio detalei) kerta paraboloidinị paviršių per vidurị, pjūviai VA2 ir VA4 yra nutolę $15 \mathrm{~mm}$ atstumu nuo VA1 pjūvio plokštumos, atitinkamai ị dešinę ir ị kairę (2 pav.). Pjūviai VA3 ir VA5 yra nutolę nuo VA1 $30 \mathrm{~mm}$ atstumu, atitinkamai ị dešinę ir ị kairę (2 pav.). Aplink detalès profilị kiekviename pjūvyje buvo parenkami 32 taškai, kurie yra vienodai nutolę vienas nuo kito.

Pjūvis HA1 (HB1 igaubto profilio detalei) yra nutolęs nuo bazinès plokštumos $7 \mathrm{~mm}$ atstumu (3 pav.), HA2, HA3, HA4, HA5 atitinkamai yra nutolę nuo bazinès plokštumos $17 \mathrm{~mm}, 27 \mathrm{~mm}, 37 \mathrm{~mm}$ ir $47 \mathrm{~mm}$ atstumais (3 pav.).
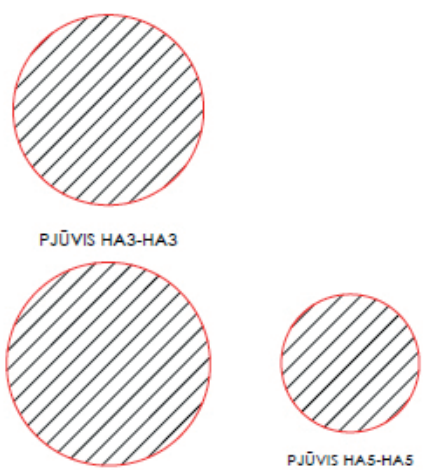

PJŪVIS HA2-HA2


PJŨVIS HAI-HAI

PJUVIS HA4-HA4

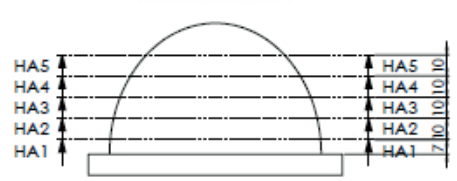

3 pav. Horizontalių pjūvių išdèstymas iškilaus profilio detalejje Fig. 3. Arrangement of horizontal sections on the convex part
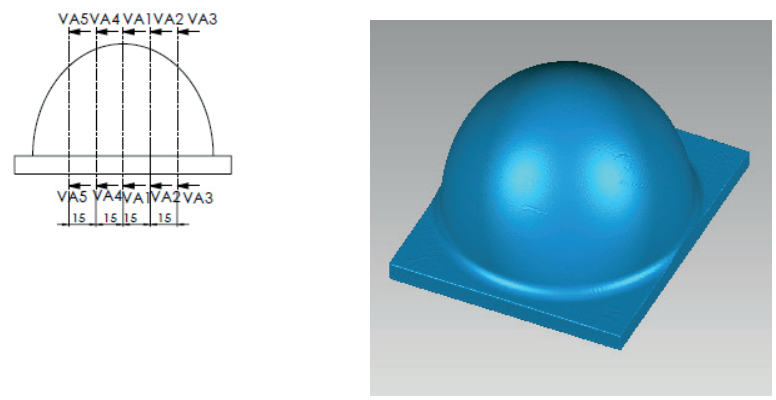

4 pav. Skenuotos iškilaus profilio detales $3 \mathrm{D}$ vaizdas

Fig. 4. 3D view of the convex part 


\section{Tyrimo metodika}

Prieš atliekant matavimus 3D lazeriniu skeneriu, sistemai kalibruoti buvo naudojami sferos ir plokštumos etalonai. Etaloninis paviršius buvo skenuojamas 3D lazeriniu skeneriu iki programinès įrangos signalo, kad sistema sukalibruota. Detalès buvo pagamintos iš aliuminio, kuris pasižymi geromis šviesos atspindejjimo savybèmis. Dèl to galèjo išsikraipyti skenavimo lazeriu rezultatai, todèl, prieš pradedant skenuoti, detalè buvo nudažoma plonu sluoksniu. Aplink skenuojamą bandini buvo pastatomi 3 taikikliai, kad lazerio sistema atpažintų erdvę. Skenuojant paviršių 3D lazeriniu skeneriu, lazerio sistema nuo detalès buvo laikoma $20-30 \mathrm{~cm}$ atstumu. Šis atstumas yra optimalus, kad skenavimo procedūra užtruktų trumpiausiai. Ant lazerio sistemos valdymo pulto yra įrengtos indikacinès lemputès, kuriomis galima nuolatos kontroliuoti reikiamą atstumą tarp lazerio galvutés ir objekto. Detalè buvo skenuojama tol, kol matomame programos lange modelyje nebeliktų aklujų zonų (4 pav.). Gautas 3D modelis buvo perkeliamas i programą „Geomagic 2014 CTR“. Ją naudojant modelis suskirstomas pjūviais, ir gauti pjūvio taškai lyginami su nominaliosiomis 3D modelio reikšmèmis. Kiekviename pjūvyje, kaip ir KMM atveju, matuojamos 32 taškų reikšmès ir nustatomi rezultatų nuokrypiai.

Norint atlikti matavimus 3D fotometriniu skeneriu, jam kalibruoti buvo naudotas plokštumos etalonas. Etalono paviršius buvo skenuojamas 3D fotometriniu skeneriu tol, kol programinè įranga sugeneruoja pranešimą, teigiantị, kad sistema sukalibruota. Sistemos matavimo tikslumui užtikrinti reikèjo padengti detalę antirefleksine danga. Juodu žymekliu ant bandinių profilių pažymimi taškai. Jie skirti tam, kad, atliekant skenavimą, neatsirastų aukščio ir gylio paklaidų. Skenuojant paviršių 3D fotometriniu skeneriu, jo sistema nuo bandinio buvo laikoma 15-25 cm atstumu. Šis atstumas užtikrina, kad skenavimo procedūra užtruktų trumpiausiai. Detalè skenuojama keturis kartus iš kiekvienos pusės tol, kol matomame programos lange modelyje neliktų aklųų zonų. Naudojant „Geomagic Studio 2014“" programą, keturių dalių skenuoti paviršiai sujungiami ị vieną, o nereikalingi, modeliui nepriklausantys taškai ištrinami. Gautas 3D modelis perkeliamas ị programą „Geomagic 2014 CTR“, čia modelis suskirstomas pjūviais ir gauti pjūvio taškai lyginami su nominaliosiomis 3D modelio reikšmėmis. Kiekviename pjūvyje, kaip KMM ir 3D lazerinio skenavimo metu, matuojamos 32 taškų reikšmès ir jų nuokrypiai nuo nominaliojo matmens. Gauti rezultatai surašomi ị lenteles ir apskaičiuojamos kiekvieno pjūvio vidutinio kvadratinio nuokrypio reikšmès. Gautos vidutinių standartinių nuokrypių reikšmės toliau buvo naudojamos rezultatams palyginti su kitų matavimo sistemų rezultatais.
Prieš atliekant matavimus KMM, kalibruoti buvo naudojama etaloninè sfera (de Aquino Silva, Burdekin 2002). Kontaktiniu liestuvu buvo matuojami 24 sferos taškai. Sukalibravus sistemą, detalès buvo matuojamos numatytuose 5 vertikaliuose ir 5 horizontaliuose pjūviuose. Kiekviename pjūvyje matuojami 32 taškai, vienodai nutolę vienas nuo kito. Naudojant programą PC-DMIS 2010 taškų koordinatès iš karto buvo lyginamos su nominaliosiomis 3D modelio koordinatėmis. Po matavimo ciklo matavimų rezultatai sugeneruojami ir pateikiama matavimų ataskaita. Gauti duomenys apie kiekvieno taško nuokrypius surašomi i lenteles. Gauti duomenys apdorojami ir apskaičiuojamas kiekvieno pjūvio vidutinis standartinis nuokrypis. Gautos vidutinių standartinių nuokrypių reikšmès toliau buvo naudojamos rezultatams palyginti su kitų matavimo sistemu rezultatais.

\section{Tyrimų rezultatai ir jų aptarimas}

Tyrimų rezultatai pateikti 5-8 pav.

Iš 5 pav. matome, kad kiekviename vertikaliame pjūvyje mažiausios vidutinès kvadratinio nuokrypio reikšmės yra gautos matuojant koordinatine matavimo mašina. Microsoft Excel 2013 programa buvo apskaičiuotas statistinis rezultatų reikšmingumas, kuriam nustatyti buvo naudotas Stjudento $t$ kriterijus ( $t$-test). Buvo gauta, kad statistiškai reikšmingai KMM matavimai yra tiksliausi $(p<0,001)$. 3D lazerinio skenerio matavimo rezultatai yra statistiškai tikslesni nei 3D fotometrinio skenerio matavimo rezultatai $(p<0,05)$.

Iš 6 pav. galima matyti, kad, matuojant iškilaus profilio detalę horizontaliuose pjūviuose, tiksliausia matavimo sistema yra KMM $(p<0,001)$.

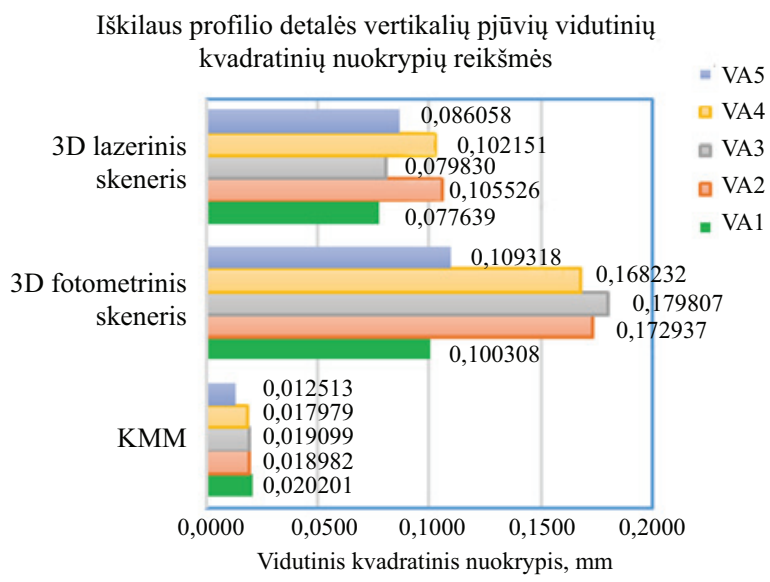

5 pav. Iškilaus profilio detalès vertikalių pjūvių matavimų rezultatų vidutinių kvadratinių nuokrypių reikšmès

Fig. 5. Standard deviation values of measurement results obtained for vertical sections of convex part 


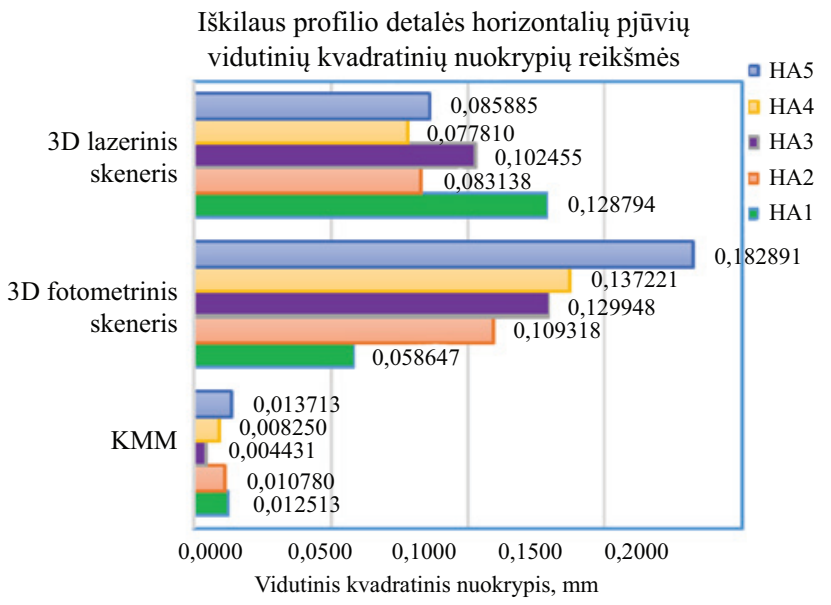

6 pav. Iškilaus profilio detalès horizontalių pjūvių matavimų rezultatų vidutinių kvadratinių nuokrypių reikšmès

Fig. 6. Standard deviation values of measurement results obtained for horizontal sections of convex part

Iš 7 pav. matome, kad, matuojant igaubto profilio detalę vertikaliuose pjūviuose, tiksliausia matavimo sistema yra taip pat KMM. Reikšmingumo ịvertinimas patvirtino, kad statistiškai tiksliausi rezultatai gauti matuojant KMM $(p<0,001)$. Tarp 3D lazerinio skenerio ir 3D fotometrinio skenerio matavimo sistemų statistiškai reikšmingų rezultatų nebuvo gauta $(p>0,05)$.

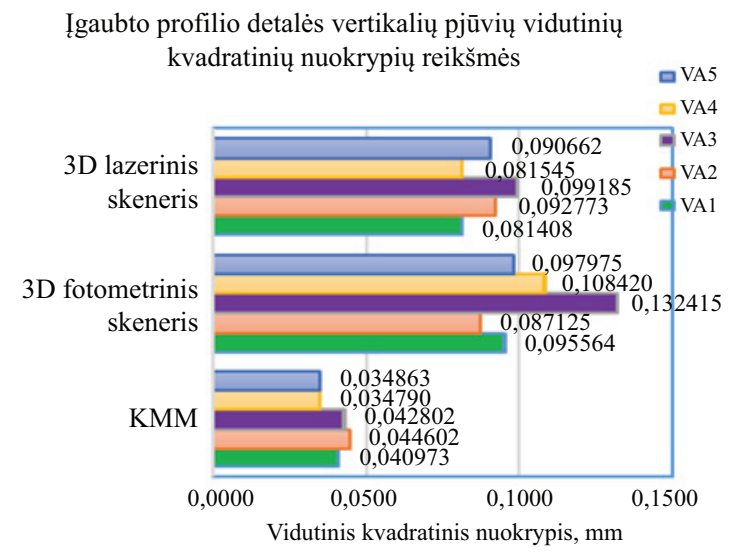

7 pav. Igaubto profilio detalès vertikalių pjūvių matavimo rezultatų vidutinių kvadratinių nuokrypių reikšmès

Fig. 7. Standard deviation values of measurement results obtained for vertical sections of concave part

8 pav. pateiktos igaubto profilio detalès matavimo rezultatų, gautų horizontaliuose pjūviuose, vidutinių kvadratinių nuokrypių reikšmès. Buvo gauta, kad statistiškai reikšmingai tiksliausi rezultatai gauti matuojant KMM $(p<0,001)$. 3D lazerinio skenerio matavimo rezultatai yra statistiškai reikšmingai tikslesni nei 3D fotometrinio skenerio matavimo rezultatai $(p<0,001)$.



8 pav. Igaubto profilio detalès horizontalių pjūvių matavimo rezultatų vidutinių kvadratinių nuokrypių reikšmès

Fig. 8. Standard deviation values of measurement results obtained for horizontal sections of concave part

\section{Išvados}

1. Tiksliausia matavimo sistema yra KMM. Matuojant iškilaus profilio detalę, visų matuotų taškų vidutinio kvadratinio nuokrypio reikšmė $\sigma=0,01347$. Naudojant Stjudento $t$ kriterijų ( $t$-test) gauta, kad rezultatai gauti KMM statistiškai reikšmingai $(p<0,001)$ tikslesni už gautus naudojant 3D lazerini skenerị ir 3D fotometrinị skenerị.

2. Matuojant igaubto paviršiaus detalę KMM sistema, visų taškų vidutinio kvadratinio nuokrypio reikšmė $\sigma=$ 0,0351 . Naudojant Stjudento $t$ kriterijų gauta, kad KMM yra statistiškai reikšmingai $(p<0,001)$ tikslesni rezultatai už gautus naudojant 3D lazerinị ir fotometrinị skenerius.

3. Matuojant tiek igaubto, tiek iškilaus profilio detales gauta, kad 3D lazerinio skenerio sistema yra statistiškai reikšmingai $(p<0,05)$ tikslesnè už 3D fotometrinio skenavimo sistemą. Atliekant matavimus lazeriniu skeneriu visų matuotų iškilaus profilio taškų vidutinis kvadratinis nuokrypis $\sigma_{i \breve{s}}=0,09341$, igaubto profilio detalès visų matuotų taškų $\sigma_{i g}=0,08793$. Atitinkamai 3D fotometrinio skenerio sistemos vidutinių kvadratinių nuokrypių reikšmės yra $\sigma_{i \breve{s}}=0,13484, \sigma_{i g}=0,13174$.

4. Pastebèta tendencija, kad, matuojant 3D fotometriniu skeneriu, didèjant detalès aukščiui mažèja matavimo tikslumas.

\section{Literatūra}

Cuypers, W.; Van Gestel, N.; Voet, A.; Kruth, J.-P.; Mingneau, J.; Bleys, P. 2009. Optical measurement techniques for mobile and large-scale dimensional metrology, Optics and Lasers Engineering 47(3-4): 292-300.

https://doi.org/10.1016/j.optlaseng.2008.03.013 
DEA Global Silver [interaktyvus]. 2015 [žiūrèta 2017 m. balandžio 27 d.]. Prieiga per internetą: http://metrology.precizika.lt/uploads/Downloads/DEA\%20GLOBAL\%20Silver.pdf\#page=1\&zoom=auto, $-103,848$

de Aquino Silva, J. B.; Burdekin, M. 2002. A modular space frame for assessing the performance of co-ordinate measuring machines (CMMs), Precision Engineering 26(1): 37-48. https://doi.org/10.1016/S0141-6359(01)00096-4

ElMaraghy, H.; Yang, X. 2003. Computer - aided planing of laser scanning of complex geometries, CIRP Annals-Manufacturing Technology 52(1): 411-414.

Galantucci, L. M.; Pesce, M.; Lavecchia, F. 2015. A stereo photogrammetry scanning methodology, for precise and accurate $3 \mathrm{D}$ digitization of small parts with sub-millimeter sized features, CIRP Annals - Manufacturing Technology 64(1): 507-510.

Gapinski, B.; Wieczorowski, M.; Marciniak-Podsadna, L.; Dybala, B.; Ziolkowski, G. 2014. Comparison of different method of measurement geometry using CMM, optical scanner and computed tomography 3D, Procedia Engineering 69: 255-262. https://doi.org/10.1016/j.proeng.2014.02.230

MetraScan 3D [interaktyvus]. 2016 [žiūrèta 2017 m. balandžio 17 d.]. Prieiga per internetą: https://www.ems-usa.com/ pdf/NEW_MetraSCAN3D_HandyPROBE_Leaflet_EN_ EMEA_13042016.pdf

Probe heads [interaktyvus]. 2015 [žiūrèta 2017 m. balandžio 27 d.]. Prieiga per internetą: http://metrology.precizika.lt/uploads/ Downloads/Probe\%20Heads.pdf
Space Spider booklet [interaktyvus]. 2015 [žiūrèta 2017 m. balandžio 17 d.]. Prieiga per internetą: https://www.artec3d.com/files/pdf/ Space-Spider-Booklet-EURO.pdf

Uekita, M.; Takaya, Y. 2016. On-machine dimensional measurement of large parts by compensating for volumetric errors of machine tools, Precision Engineering 43: 200-210. https://doi.org/10.1016/j.precisioneng.2015.07.009

\section{A COMPARATIVE ANALYSIS OF MEASUREMENT RESULTS OBTAINED IN MEASURING PARTS HAVING COMPLEX GEOMETRIC SHAPES BY MEANS OF 3D SCANNERS AND CMM}

\section{Ž. Graibus, V. Mokšin}

Abstract

This study compares the dimension measurements results obtained for two parts that had convex and concave parabolic profiles. Three different measurement systems were employed for measurements: coordinate measuring machine (CMM), 3D laser and 3D photometric scanners. It was found using Student's $t$ - test that results obtained by CMM measuring system are statistically significantly $(p<0.001)$ more accurate than results obtained by means of $3 \mathrm{D}$ laser and $3 \mathrm{D}$ photometric scanners. It was also established that results obtained by means of 3D laser scanning system are statistically significantly more accurate $(p<0.05)$ than those obtained by means of 3D photometric scanning system.

Keywords: CMM, photometric scanner, laser scanner, 3D model. 